\title{
Experimental Validation of EnergyPlus® Simulation of a Single Storey Building
}

\author{
Azhaili Baharun, Siti Halipah Ibrahim, Mohammad Omar Abdullah, Ooi Koon Beng*
}

\begin{abstract}
EnergyPlus ${ }^{\circledR}$ simulated indoor temperatures of a single storey building at the east campus of Universiti Malaysia Sarawak, for April and June, are validated with measurements taken in 2007.

The measured local outdoor temperature was used together with the global solar radiation, wind velocity, relative humidity and cloud cover measured at the Kuching airport to replace the typical meteorological year (TMY) values in the EnergyPlus ${ }^{\circledR}$ weather (EPW) file to form a Modified EPW weather file at the time/date of experiments. The remaining fields of the Modified EPW contain TMY data including the direct and diffuse solar radiations and the 'sky's' infrared radiation, which is also present at night.
\end{abstract}

Analysis of the temperatures at the windows simulated with the EPW and Modified EPW weather files for the April and June experiments show the strong influence of the outdoor temperature and importance of the global solar radiation in the weather file and local outdoor temperature is used in the Modified EPW.

Day time peak mismatches between the measured indoor air temperature and the indoor air temperature simulated with the Modified EPW is 2 to $3 \mathrm{deg}$ C. These are due to the use of the TMY direct and diffuse solar radiations in the heat balance algorithms at the outside surfaces. The corresponding night time mismatches are less than 1 deg $\mathrm{C}$ because the TMY values of the long wave infra-red radiation emitted from molecules and particles in the atmosphere in the Modified EPW are used in simulation.

Keywords: Validation, EnergyPlus®, solar and sky radiations, single story classroom, measuring probes

\section{I.INTRODUCTION}

$\mathrm{O}$ utdoor and indoor air and inside surface temperatures were measured at a single story classroom Bilik Seminar 1 (BS1) in the Universiti Malaysia Sarawak (UNIMAS) east campus in April and June 2007. The campus is located at latitude 1.46 degrees north and longitude 110.41 degrees east. The weather station is at the airport is located at 1.48 degrees north and longitude 110.33 degrees east.

Figure 1.1 shows the model of the experimental single story building, Bilik Seminar 1 (BS1), generated from the input file for simulation.

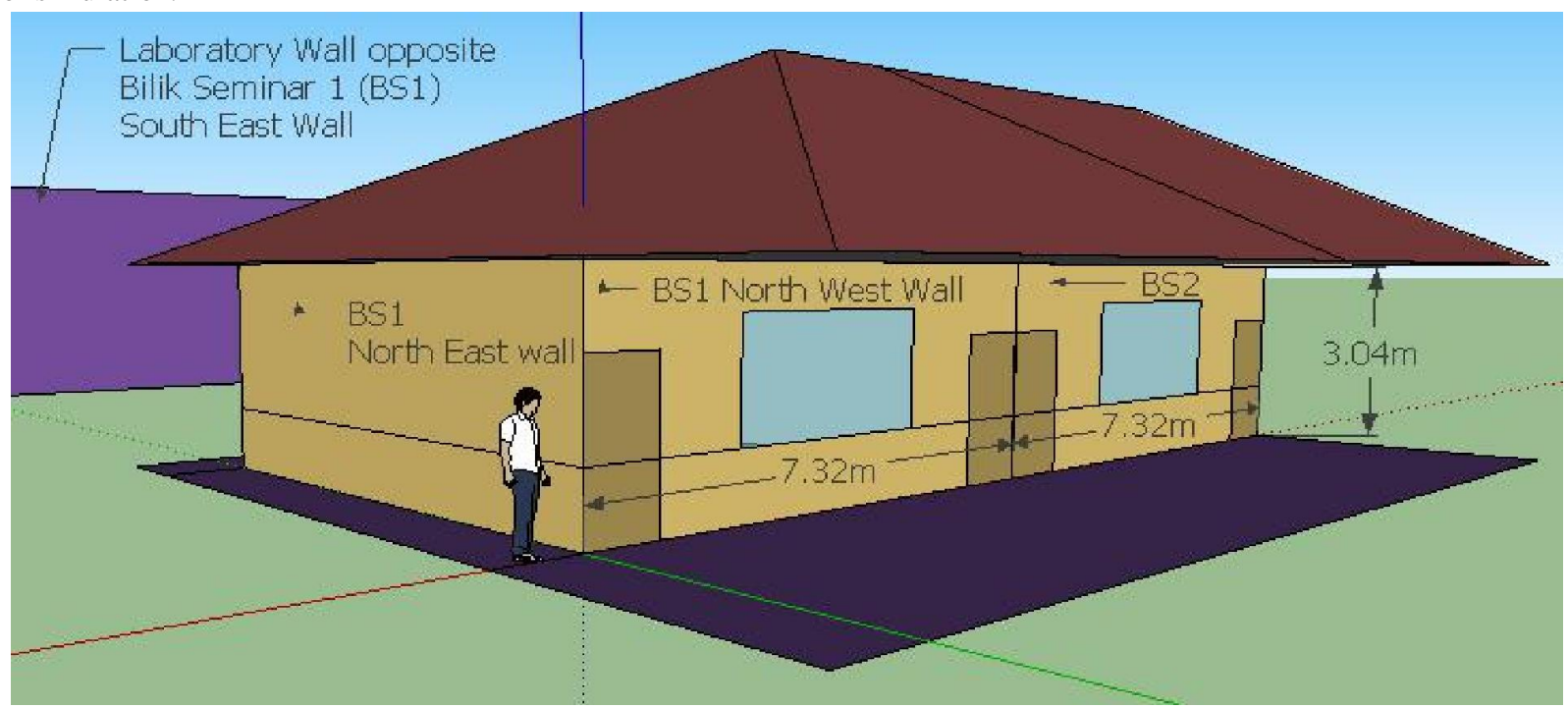

Figure 1.1 Computer generated diagram of the classroom, viewed from north. 


\section{UNIMAS e-Journal of Civil Engineering}

The width of the classroom in the X-direction is 7.32 meters and in the Y-direction is 7.52 meters. The 2.94 meter wide and 1.56 meter tall South East and North West windows sit on the 0.9 meter high bottom brick wall. The ceiling height is 3.04 meters. The roof above the attic overhangs the South East wall by 1.1 meters and the North West wall by 4 meters. The doors and vertical blinds for the windows were closed during the experiments.

\section{MATERIALS USED IN THE SINGLE STORY BUILDING}

Figure 2.1 shows the constructions of the layers of materials for the surfaces of the classroom/s.

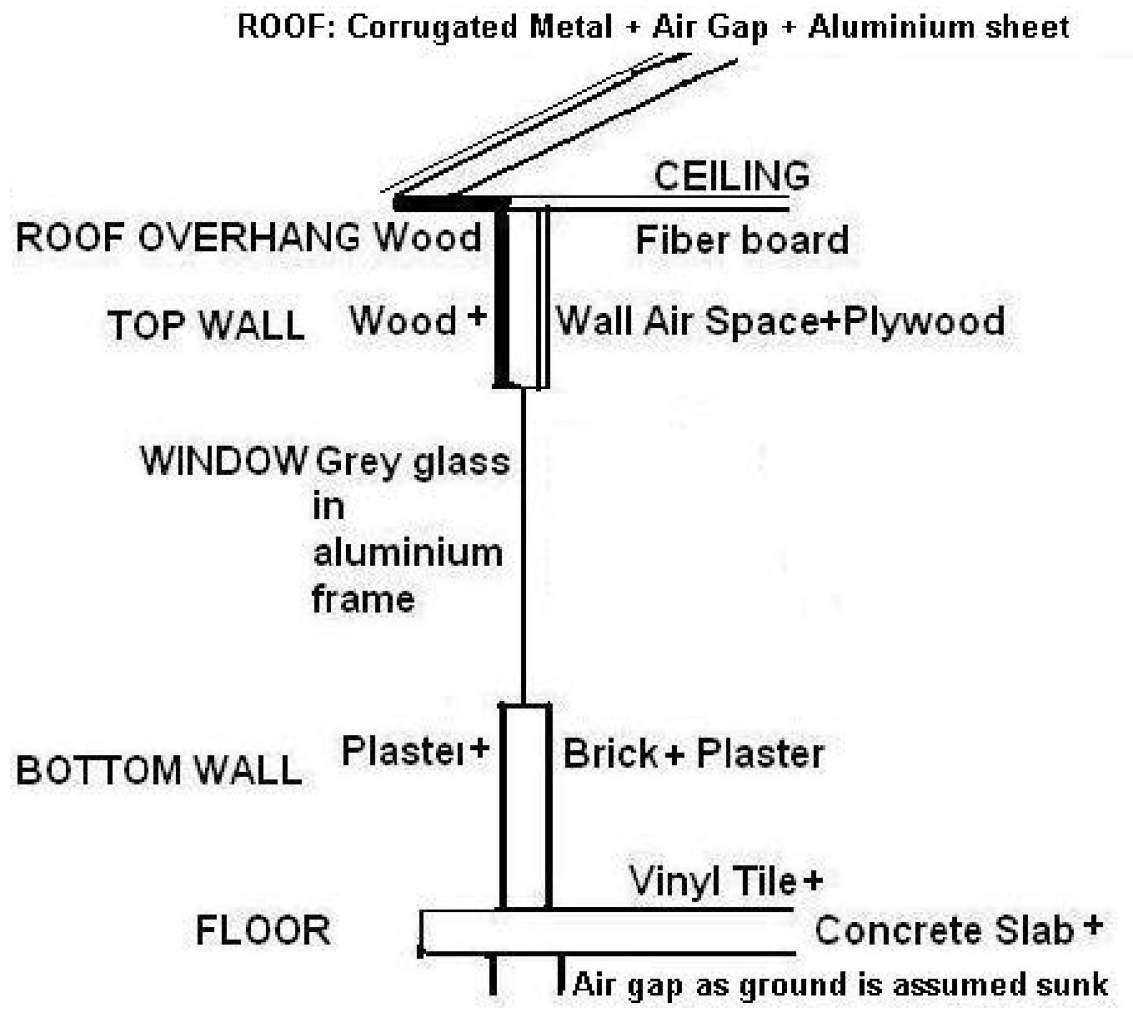

Figure 2.1 Arrangement of the layers of materials for surfaces of classroom

Table 2.1 indicates the U-values, manually calculated with 'fixed' convection and radiation coefficients. EnergyPlus ${ }^{\circledR}$ uses heat balance computations at the outside and inside surfaces from algorithms with selectable convective coefficients. The convection algorithms for the outside surfaces switch the convective coefficients to high values so that the outside temperatures of surfaces declared as wind-exposed, become the wet bulb temperatures, if rain is indicated in the weather file and made active in the input file.

Table 2.1. Constructions for the surfaces of building envelope (indicative U-values).

\begin{tabular}{|l|c|c|c|c|c|c|}
\hline & Bottom Wall & Top Wall & Window & Ceiling & Roof & Floor \\
\hline Outside Layer & Plaster & Wood & Grey Glass & Fibre Board & Metal & Air gap $^{\text {a }}$ \\
\hline Middle Layer & Clay Bricks & Air Space & --- & --- & Air gap $^{\mathrm{a}}$ & Cast Concrete $^{\mathrm{a}}$ \\
\hline Inside Layer & Plaster & Plywood & --- & --- & Alum sheet & Vinyl Tile. \\
\hline $\begin{array}{c}\text { Indicative } \\
\text { U-value }\left[W /\left(\mathrm{m}^{2}-\mathrm{k}\right)\right.\end{array}$ & 2.45 & 1.88 & 3.91 & $4.41^{\mathrm{b}}(\mathrm{Up})$ & $1.93^{\mathrm{b}}(\mathrm{Up})$ & $2.29^{\mathrm{b}}(\mathrm{Up})$ \\
\cline { 4 - 7 } & & & & $3.5^{\mathrm{b}}(\mathrm{Down})$ & $1.5^{\mathrm{b}}(\mathrm{Down})$ & $2.03^{\mathrm{b}}(\mathrm{Down})$ \\
\hline
\end{tabular}

${ }^{\mathrm{a}} \mathrm{R}$-value of the vertical air space is $0.143 \mathrm{~m}^{2}-\mathrm{K} / \mathrm{W}$ and 'horizontal' air gaps is $0.15 \mathrm{~m}^{2}-\mathrm{K} / \mathrm{W}$ from ASHRAE Handbook of Fundamentals (HOF)[1]. Combined convection and radiation heat transfer coefficients from ASHRAE HOF Ref 1, Chapter 22, Table 1. Shown on in Table 3.7 Page 175, 'Heat Transfer, A Practical Approach (Second Editon)' by Cengel[2]

1 The U-values are indicative as they are manually calculated using 'constant' coefficients 


\section{UNIMAS e-Journal of Civil Engineering}

III.

The EnergyPlus ${ }^{\circledR}$ weather file (EPW) has about 27 fields with hourly data or information for a typical meteorological year (TMY). EnergyPlus documentation states that 12 of these 27 fields are used in simulation. The Meteorological Department of Malaysia (MET) provided data for 5 weather variables, the outdoor temperature, global horizontal radiation, wind speed, wind direction, relative humidity, and cloud cover measured at the airport. The outdoor temperature was also measured locally at the experimental classroom.

\subsection{Outdoor Temperature measured locally at the classroom, for the Modified EPW.}

Figure 3.1 shows the measuring probe for the outdoor and indoor air temperatures at the classroom. An aluminum foil cup surrounds the thermocouple junction.

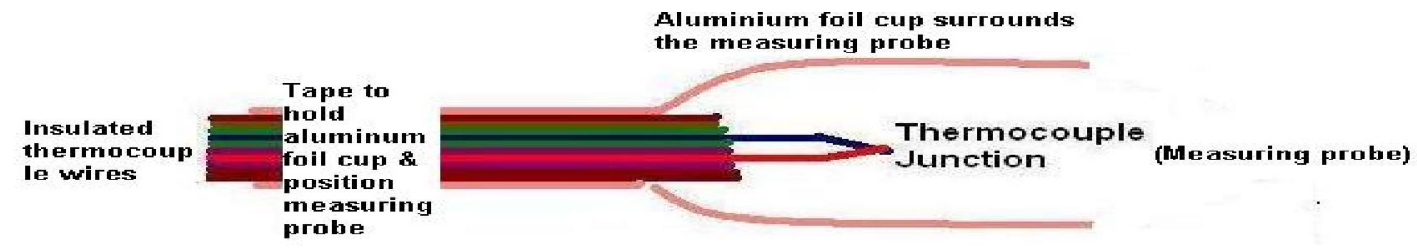

Figure 3.1 Measuring probe for local outdoor and indoor air temperatures

The left of Figure 3.2 shows this measuring probe for the outdoor air temperature at the North West (NW) wall of Bilik Seminar 1 . The right of figure 3.2 shows the probe for the indoor air temperature in the centre of the classroom. It is beside the black globe at the center.

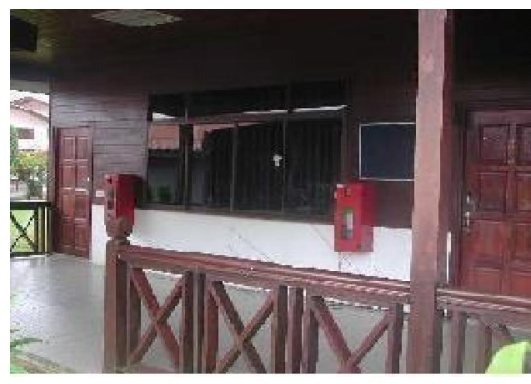

Location of measuing probes at classroom Bilik Seminar 1 (BS1).

Left: NW Wall. Probe for local outdoor temperature (BSI_ODT) is above right red box.

Right: Probe for indoor air temperature is in the center of the classroom, next to the globe

Figure 3.2 Location of outdoor and indoor air temperature measuring probes.

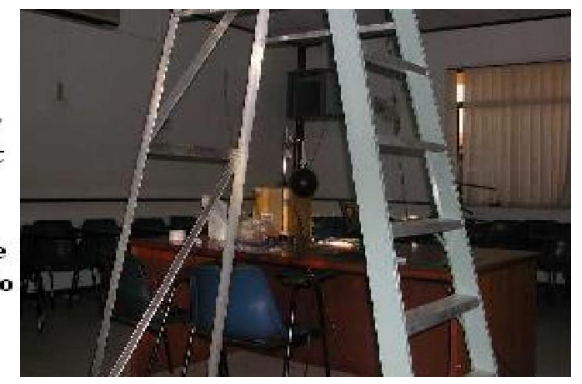

Figure 3.3 shows 'spurs' in the 10-minute readings of the outdoor temperature measured at the classroom, during the 7 day June experiment. The opening in the measuring probe, shown in Figure 3.1 picks up 'spurious' radiations reflected from walls, ground, sky or from lights. These radiations were removed by drawing a smooth line under the 'spurs' to obtain the hourly local outdoor temperature, BS1_ODT used in the 'Modified EPW'.

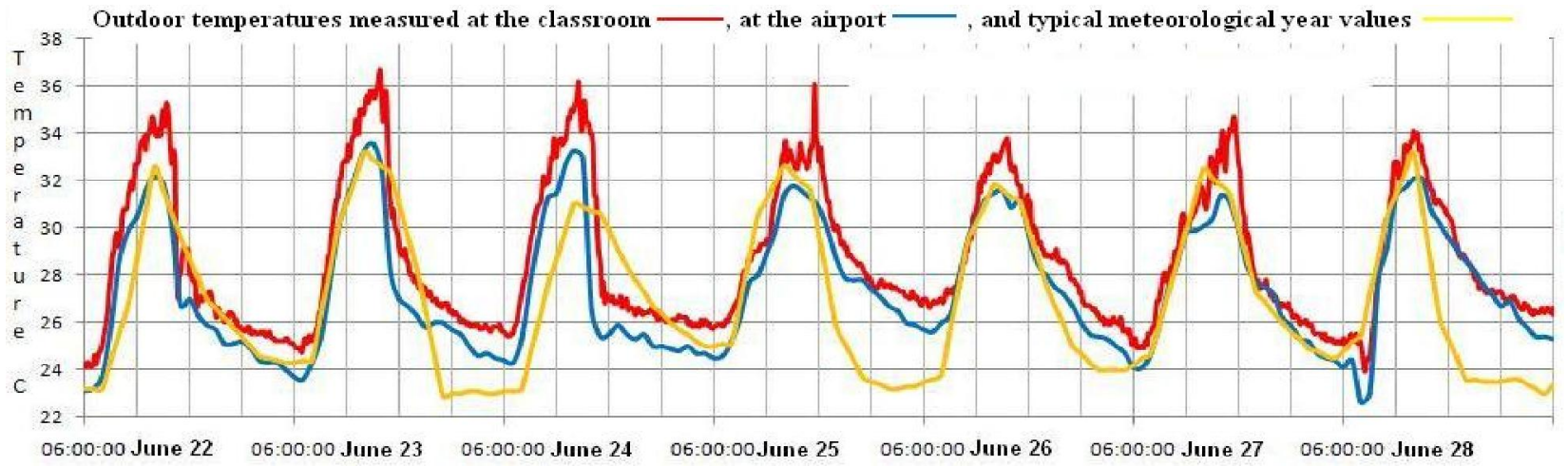

Figure 3.3 Outdoor temperatures measured at classroom, at airport and typical year values

To simulate for the indoor temperatures, a 'Modified EPW' at the time/date of the experiments was created by using the local outdoor temperature, and the data measured at the airport for the other weather variables including the global solar radiation.

The window glass temperatures simulated with EPW and Modified EPW are used to show the influence of the outdoor temperature and global solar radiations in the weather file. Section 3.2.1 analyses the combined effect of outdoor temperature and radiation in the April experiment and Section 3.2.2 analyses effect of outdoor temperature in the June experiment. 


\section{UNIMAS e-Journal of Civil Engineering}

\subsubsection{Effect of outdoor temperature and global solar radiation in the weather file on simulated indoor temperatures.}

The importance of the outdoor temperature and the global solar radiation in the weather file is shown by simulated results using the EPW and Modified EPW. The inside surfaces of South East and North West windows simulated with the EPW and Modified EPW are shown at the left and right of Figure 3.4 for two days of the April experiment.

At 8 am on April 21 and 11 am on April 22, the temperatures simulated with the EPW crosses the temperatures simulated with the Modified EPW. At these times, the local outdoor temperature, BS1_ODT is nearly equal to the typical year outdoor temperature, TMY_ODT and the measured global horizontal radiation is also nearly equal to the 'typical year' global horizontal radiation. The values are $26^{\circ} \mathrm{C}$ and $95 \mathrm{Wh} / \mathrm{m}^{2}$ at $8 \mathrm{am}$ on April 21 and $29.5^{\circ} \mathrm{C}$ and $500 \mathrm{Wh} / \mathrm{m}^{2}$ at $11 \mathrm{am}$ on April 22. This verifies that outdoor temperature and the global horizontal radiation are important data in the weather file.

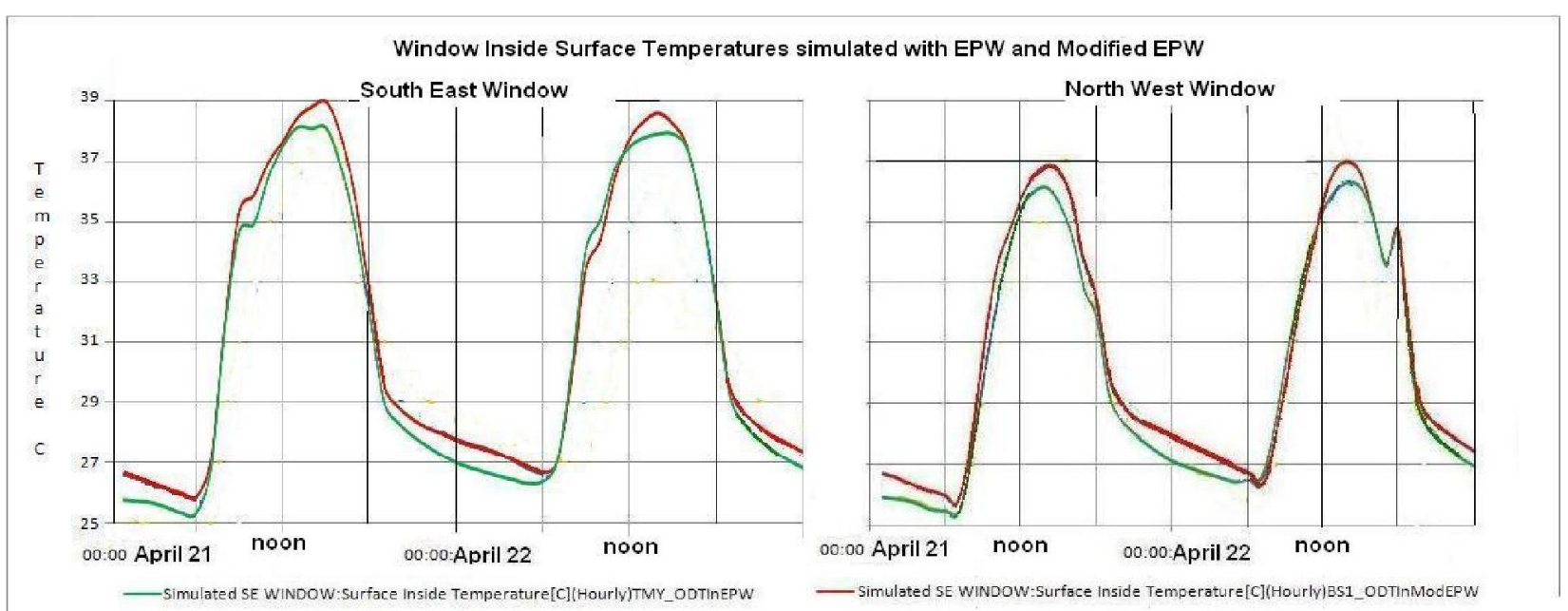

Figure 3.4 Inside surface temperatures of windows simulated with EPW and Modified EPW

The radiation measured at the airport is the global solar radiation. However, the heat balance computations in the simulations does not use this field in the weather file but use the data for the direct and diffuse solar radiations. The direct solar radiation is the sun's radiation that reaches the earth without being absorbed or scattered by the atmosphere. The diffuse solar radiation is the sun's radiation that reaches the earth after scattering and absorption by the atmosphere.

\subsubsection{The effect of only the outdoor temperature in the weather file.}

Figure 3.5 shows that the inside surface temperatures of the North West window in the June experiment, simulated with EPW and Modified EPW on June 22 and 23 are within 1 degree $C$ from 4 pm to $10 \mathrm{pm}$. During this 6 hour period, the local outdoor temperature, BS1_ODT and the typical meteorological year outdoor temperature (TMY_ODT), shown in Figure 3.3 are very close. This shows that the data in the outdoor dry bulb temperature fireld in the weather file is influential.

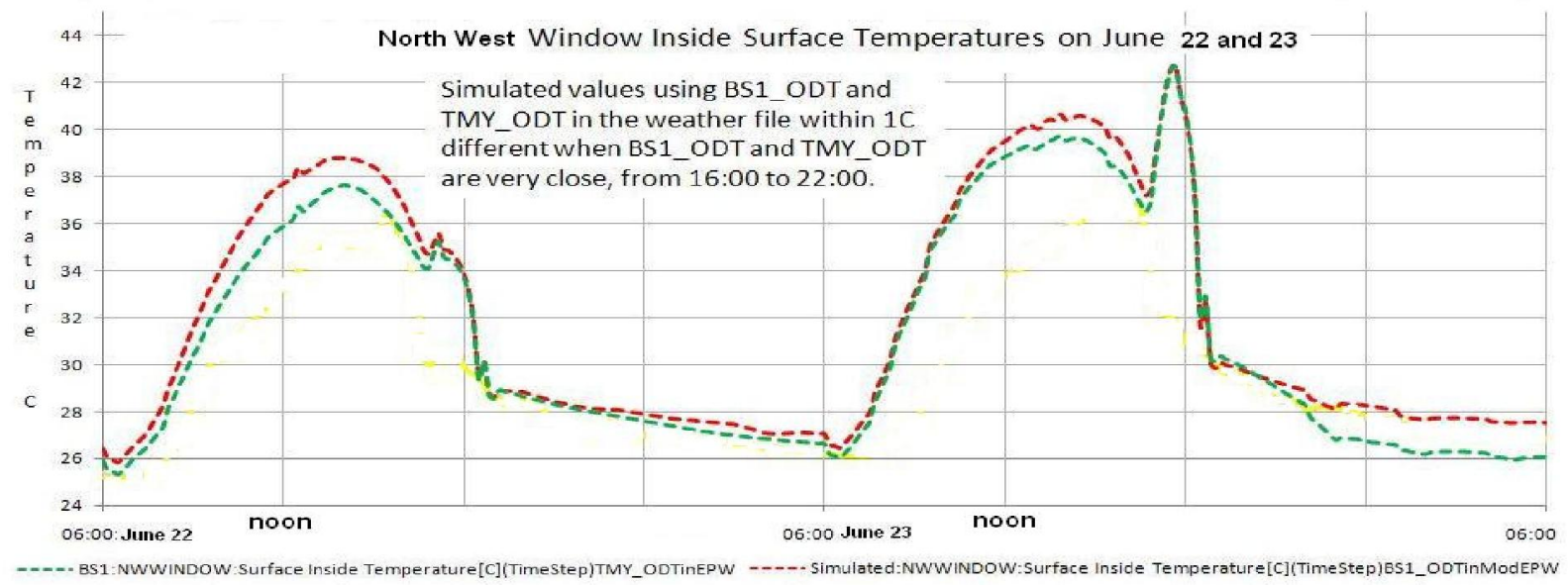

Figure 3.5. Inside surface temperature of window simulated with EPW and Modified EPW, June 22 and 23

Therefore, the outdoor temperature measured locally at the time/date of the experiments must be used in the Modified EPW. But, in simulation, the heat balance algorithm at the external surface uses the direct normal and diffuse horizontal solar radiation and the infrared horizontal radiation in the weather files. The effect of the use of TMY data for the direct and 


\section{UNIMAS e-Journal of Civil Engineering}

diffuse radiations that are present during the day, and the infra red radiation present all the time, will be shown in the results in the next section.

\section{RESULTS}

Figures 4.1 and 4.2 show the mismatches between the measured and simulated indoor air temperatures for the April and June experiments respectively. The peak mismatches during day time, shown shaded in yellow are about 2 to 3 deg $\mathrm{C}$ and the mismatches during night time, shown in blue are about $1 \mathrm{deg} \mathrm{C}$.

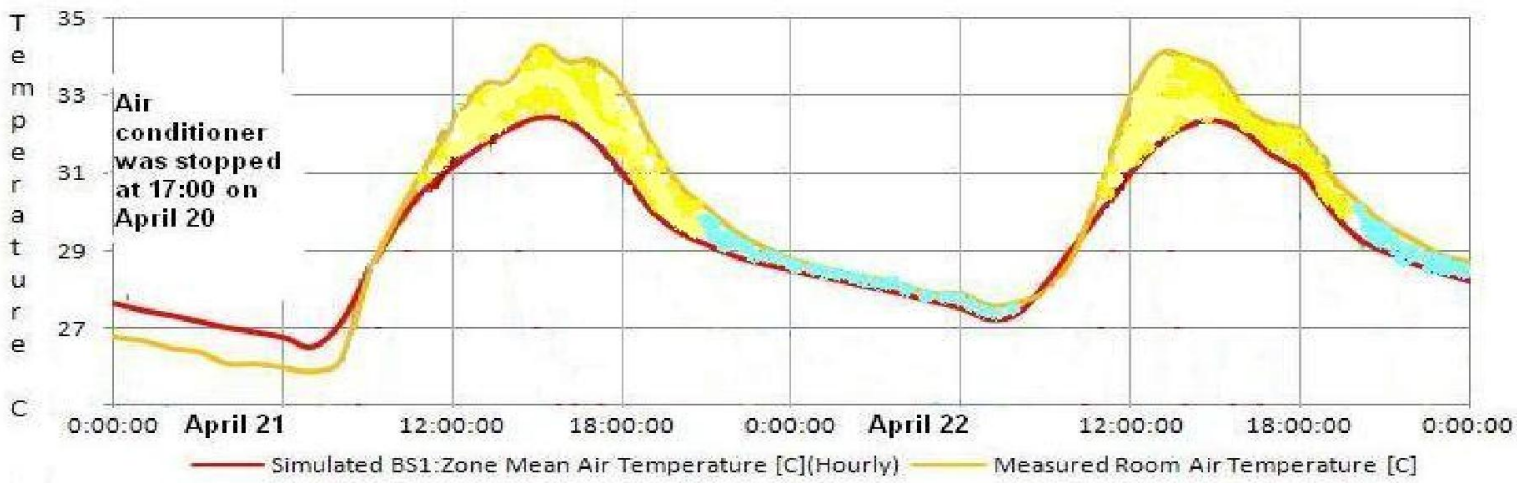

Figure 4.1 Mismatches between measured and simulated indoor air temperatures April 21 and 22

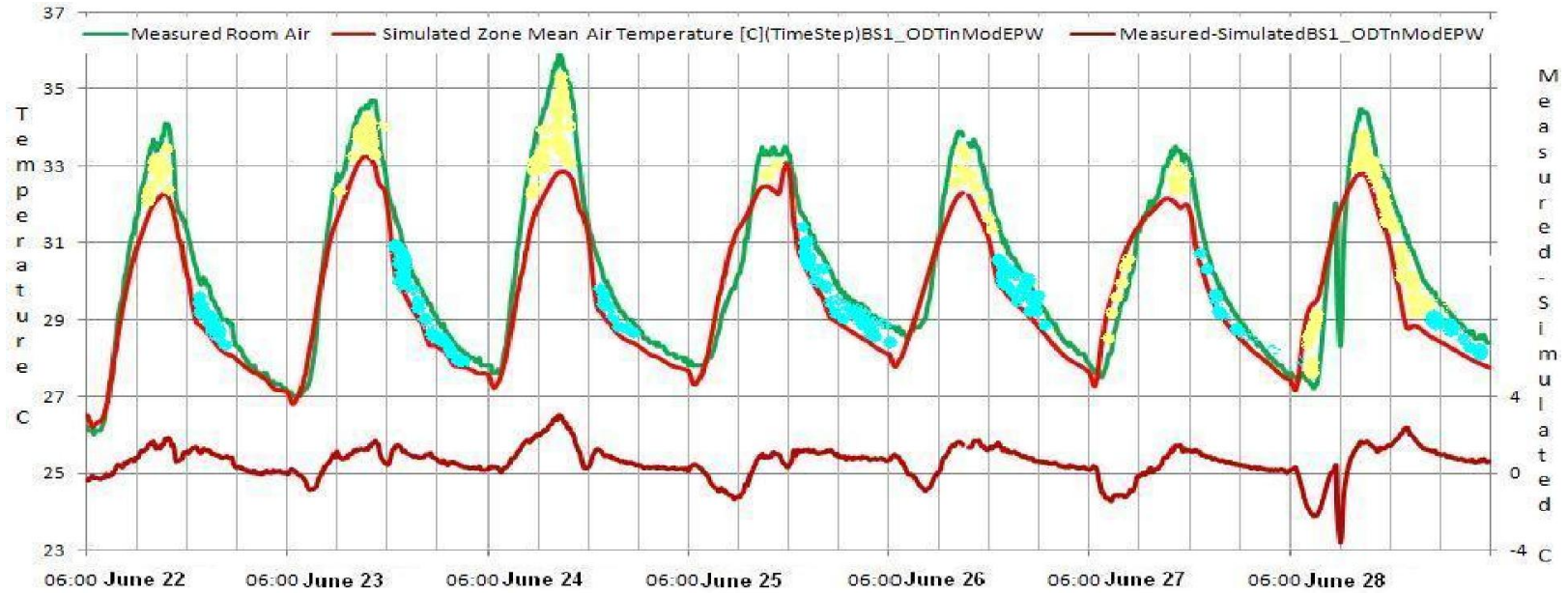

Figure 4.2 Mismatches between measured and simulated indoor air temperatures, June.

The peak mismatches occur around midday when the global solar radiation is about $1 \mathrm{KW} / \mathrm{m}^{2}$. In the EPW, the TMY global horizontal radiation is the vectorial sum of the TMY direct normal radiation and the TMY diffuse horizontal radiations. The TMY direct normal and diffuse horizontal radiations are in the Modified EPW.

Long wave infrared radiation is emitted by the molecules and particles in the atmosphere. The horizontal infra red radiation in the EPW is around half a $\mathrm{KW} / \mathrm{m}^{2}$ and at night, it is lower at about $450 \mathrm{~W} / \mathrm{m}^{2}$.

\section{V.DISCUSSION.}

The outdoor temperature is the influential data in the weather file. Thus, for simulation the outdoor temperature measured locally at the experimental classroom was processed and used in the weather file for simulation.

In EnergyPlus ${ }^{\circledR}$, the heat balance computations at the outside surfaces consider the shortwave radiation including direct, reflected and diffuse sunlight, longwave radiation from the environment and convective heat exchange with the outside air. For future experiments, the methods to obtain values for the direct normal and diffuse horizontal solar radiations and the horizontal infrared radiation are now presented.

\subsection{Obtaining Direct and Diffuse solar radiations at time/date of experiment.}

Prior arrangements may be made, through the Meteorological Department for the forecaster taking readings of the global horizontal radiation at the airport to cast a shadow over the sensor. The reading should then be the diffuse horizontal radiation and can be used in the Modified EPW. The global horizontal radiation minus the diffuse horizontal radiation is the direct horizontal radiation. The direct normal radiation for the Modified EPW is the direct horizontal radiation divided by the 


\section{UNIMAS e-Journal of Civil Engineering}

sine of the solar altitude angle. The solar altitude angle is the angle the direct beam from the sun makes with the horizontal. The solar altitude angle can be obtained by measuring the length of the shadows of a vertical pole or can be read from sun path diagrams.

\subsection{Obtaining Infra-red radiation at time/date of experiment.}

Measurements of the opaque sky cover, or the amount of sky completely hidden by clouds or obscuring phenomena ( $\mathrm{N}$, in tenths), is necessary in order to calculate the sky emissivity, given by the following formula reproduced from page 101 of the EnergyPlus ${ }^{\circledR}$ version 5 Engineering Reference.

$$
\begin{aligned}
S k y_{\text {emissinity }}= & \left(.787+.764 \cdot \ln \left(\frac{\text { Temperature }_{\text {deipoint }}}{273 .}\right)\right) \cdot\left(1 .+.0224 N+.0035 N^{2}+.00028 N^{3}\right) \\
& \text { where } \\
& \text { Temperature }_{\text {dewpoint }}=\text { dewpoint temperature }[\mathrm{K}\}
\end{aligned}
$$

The dew point temperature $(\mathrm{K})$ can be obtained from the wet and dry bulb temperatures measured at the airport.

The horizontal infrared radiation is then calculated from the following:

Sky emissivity x Stefan-Boltzmann constant $\mathrm{x}$ [Dry bulb outdoor temperature (in Kelvin) $]^{4}$.

Crawford and Duchon [3] (1999) present another way to obtain the infra red radiation from sky. It needs many more measurements and observations of temperature, humidity, pressure, and solar radiation.

\section{VI.CONCLUSION}

The EnergyPlus® building simulation software uses detailed heat balance computations for surfaces and the indoor air. EnergyPlus ${ }^{\circledR}$ building simulation software may be used to evaluate the indoor temperatures for a passive Malaysian building.

\section{ACKNOWLEDGMENT}

The authors would like to acknowledge the help of the Kuching office of the Meteorological Department, Malaysia for supplying the weather data at the airport The authors would like to thank the all staff of University Malaysia Sarawak, especially LaboratoryTechnician Rozaini of the Building Services Laboratory, Faculty of Engineering, and Puan Bunia for the use of the single story classroom Bilik Seminar 1.

\section{REFERENCES}

[1] ASHRAE Handbook of Fundamentals 2005

[2] Cengel YA, "Heat Transfer, A Practical Approach (Second Edition)" McGraw-Hill Higher Education, ISBN 0-07245893-3, ISBN 0-07-115150-8(ISE)

[3] Crawford T.M. and Duchon C.E. An improved parameterization for estimating effective atmospheric emissivity for use in calculating daytime down welling long-wave radiation Journal of Applied Meteorology. 38 (4) pp 474-480 (1999) 